\title{
Purchasing green to become greener: Factors influence consumers' green purchasing behavior
}

\author{
Hosein Vazifehdoust ${ }^{\mathrm{a}}$, Mohammad Taleghani ${ }^{\mathrm{b}}$, Fariba Esmaeilpour ${ }^{\mathrm{c}^{*}}$, Kianoush Nazaric and Mahdie \\ Khadang ${ }^{\text {d }}$
}

${ }^{a}$ Assistant professor, Department of Business Management, Science and Research Branch, Islamic Azad University, Tehran, Iran

${ }^{b}$ Assistant professor, Department of Business Management, Rasht Branch, Islamic Azad University, Rasht, Iran

${ }^{c}$ PhD student in Marketing Management, Department of Business Management, Science and Research Branch, Islamic Azad University, Tehran, Iran ${ }^{d}$ PhD student in Marketing Management, Department of Business Management, Tehran Central Branch, Islamic Azad University, Tehran, Iran

\begin{abstract}
A B S T R A C T
This study proposes an integrated model that combines the Theory of Reasoned Action (TRA) and two categories of variables, personal and marketing, to investigate the attitudinal and behavioral decision factors to purchase green products. The model derived and tested via structural equation modeling on a sample of 374 consumers from the Guilan province in Iran. The results show that attitude is explained by consumers' environmental concern, quality of green products, green advertising and green labeling. The results of the structural equation analysis indicate that attitude positively influences intention to purchase green products. Green purchasing intention also influences on green purchasing behavior. This paper also discusses the implications of the results for marketers and researchers.
\end{abstract}

\section{Introduction}

There has been a rising concern on environmental issues worldwide. Today's consumers have started to realize that their purchasing behavior actually can cause a huge impact on environment. Therefore, being socially responsible by offering environmentally friendly products and services should be a practice of any companies who wish to sustain a competitive advantage in the business world (Abdul Wahid et al., 2011). Environmental issues as so important that many governmental organizations around the world have been trying to prepare necessary laws and regulations to protect the environment. For instance, the Restriction of Hazardous Substances (RoHS) of the European Union restricts the use of six toxic materials in the manufacture of all electronic and electrical equipment. Meanwhile, consumers are paying more attention to purchase environmentally friendly goods and 
materials. They are increasingly willing to purchase eco-friendly or so called green products even though these products are often more expensive (Sua et al., 2012). The recent concern for the consequences of global climate change has sensitized the consumer to look for the well-being of future generations. Indeed, environmental consumer issues are clearly evolving as a product of a fundamental democratic process, in which citizens are demanding a safer and healthier environment because of seeking more information on a given product and its production process, while balancing the costs with the benefits of the product (OSEC, 2009).

The customer and product is the challenge of every business, and meeting customer needs is a motive of good manufacturing practice. In order to meet the consumers' requirements for a product to be acceptable to customers, quality and cost of product, the products' performance and even environmental issues should be considered (Zakersalehi \& Zakersalehi, 2012). The potential benefits of green products and green organizations in a competitive environment have been discussed for several years. For example, Porter and van der Linde proposed that well-crafted regulations could drive innovation and positive outcomes, which could compensate for the cost of those regulations. Friedman examined the relationship among global environmental, economic and political issues and argued that the United States should develop a green revolution. He proposed that green technology not only benefits the environment but also the consumer and economy by developing new products and markets (Drozdenko et al., 2011).

This paper will focus specifically on the green products. In addition, the purpose of this study is to seek to broaden the understanding of what factors influence on purchasing green products by consumers.

\section{Literature review}

\subsection{Green Product}

The environmental products and services market or more commonly called Environmental Technologies market is defined by those environmental technologies that advance sustainable development by reducing risk, enhancing cost effectiveness, improving process efficiency and creating products and processes that are environmentally beneficial or benign. Environmental sustainability in business is the art of profiting from the customers' needs without harming the world around us. The terms Clean Technologies and Green Technologies are frequently applied interchangeably with Environmental Technologies. Subtleties consist of the latter being driven by the requirements of existing regulatory standards, whereas the former two terms are almost identical, one addressing regulations and public awareness and the other addressing regulations and directly responding to society's green values, both leaving room for free market mechanisms. In the world of finance, Clean Technologies represent new technology related business models that offer competitive returns to investors and consumers while providing solutions to global challenges (OSEC, 2009). In general, green product is known as an ecological product or environmental friendly product. Some people define green product as "the product that will not pollute the earth or deplore natural resources, and can be recycled or conserved". It is a product that has more environmentally sound content or packaging in reducing the environmental impact. In other words, green product refers to product that incorporates the strategies in recycling or with recycled content, reduced packaging or using less toxic materials to reduce the impact on the natural environment (Chen \& Teck Chai, 2010).

\subsection{Green purchasing behavior}

Environmentally Preferable Purchasing (EPP), often referred to as "green purchasing", is the affirmative selection and acquisition of products and services that most effectively minimize negative environmental impacts over their life cycle of manufacturing, transportation, use and recycling or 
disposal. Examples of environmentally preferable characteristics include products and services that conserve energy and water, minimize generation of waste and releases of pollutants; products made from recycled materials and that can be reused or recycled; energy from renewable resources such as bio based fuels, solar and wind power; alternate fuel vehicles; and products using alternatives to hazardous or toxic chemicals, radioactive materials and bio hazardous agents. In simple words, green purchasing is adding environmental characteristics to price and performance criteria when making purchasing decisions. The primary goal is to reduce environmental impacts of sourcing and to increase resource efficiency. Green purchasing is the practice of applying environmental criteria to the selection of products or services. It takes a number of forms, from relatively simple to relatively complex. It is now relatively common among larger companies and appears to be increasingly used as a corporate practice (Shah, 2002).

\subsection{Theory of Reasoned Action (TRA)}

Central to TRA is the concept of intention, which Ajzen described as an individual's motivation in his/her cognizant plan/decision to exert an effort in performing a specific behavior. According to TRA, most human behaviors are predictable based on intention because such behaviors are volitional and under the control of intention. That is, people, in their decision processes, have a high degree of volitional control and, thus, make reasoned choices among alternatives (Han \& Hsu, 2010).

Some researchers developed and explicated the TRA to account for mechanisms of human behaviors in decision processes. In their investigation of the effectiveness of TRA, which involved use of a meta-analysis, Sheppard et al. verified the predictive power of TRA. Their findings indicated that the model accurately predicted individuals' decisions and behaviors when applied in any situation or to any activity. Because of its accuracy in forecasting human behaviors and effectiveness in explaining psychological processes in decision-making, the TRA has been widely utilized in comprehending customers' decision-making processes in various contexts (Han \& Kim, 2010). According to TRA, behavioral intention is a function of two factors; namely, attitude toward performing the behavior and subjective norm (Han \& Hsu, 2010).

\subsection{Attitude and Intention to green purchasing}

Recognizing the seriousness of environmental problems possibly caused by excessive use of energy and non-renewable natural resources, copious supplies of foods and products, environmentally unfriendly production processes, and environmental disasters, increasing numbers of individuals are aware of environmental issues and feel our natural resources are limited and the environment is more fragile than we once believed. Such environmental awareness instills in the public a positive attitude toward eco-friendly activities, and encourages people to more frequently engage in ecological behaviors in their everyday lives (Han \& Hsu, 2011).

Attitudes are sets of beliefs about a certain object or an act, which may translate into intention to carry out the act. Intention on the other hand is a determination to act in a certain way (Ramayah et al., 2010). Attitudes are the favorable or unfavorable evaluation an individual forms of a specified behavior. Attitudes impact the intentions held and the more favorable the attitude, the bigger the intention to perform the behavior will be. In addition, attitudes are predictors of purchase intentions and consequently purchase behavior. Moreover, attitudes are necessary, as consumers require an understanding of their attitudes and motivations in order to overcome the perceived purchase barriers they face (Smith \& Paladino, 2010).

Many studies show that the attitude-behavior relationship has been strengthened when attitudes towards performing specific environmentally friendly behavior (e.g., recycling), rather than towards 
general environmental issues. In general, empirical studies have implied a substantial positive relationship between ecological intention and behavior (Chan, 2001). The bigger the positive attitudes, the more likely the intention to buy will be and therefore, the greater the likelihood that consumer will purchase green products over conventional alternatives. A mediator has been described as "the generative mechanism through which the focal independent variable is able to influence the dependent variable". The TRA indicates that mediation effects will impact the relationships formed. Therefore, this report examines the effect of mediators (Smith \& Paladino, 2010) as follows.

$H_{1}$ : A positive attitudes towards green products has a positive effect on the consumers' Intentions of purchasing green products.

$\mathrm{H}_{2}$ : Consumers' green purchasing intentions has a positive effect on the consumers' Intentions of purchasing green products.

\subsection{Antecedents}

\subsubsection{Environmental Knowledge}

The attitudes of consumers to purchase green products are made up of their beliefs and knowledge towards the concept of green products, which they accumulate from their lifetime. Environmental knowledge can be defined as a general knowledge of facts, concepts, and relationships concerning the natural environment and its major ecosystems. In other words, environmental knowledge involves what people know about the environment, key relationships leading to environmental aspects or impacts, an appreciation of "whole systems", and collective responsibilities necessary for sustainable development. Attaining a high level of environmental knowledge produces much better proenvironmental behavior. Environmental knowledge has a significant impact on the consumers' intention to buy green products (Kaufmann et al., 2012).

The mixed empirical findings may well suggest a more complex relationship between ecological knowledge and behavior. The purchase experience and knowledge gained from each purchase process (as well as the guilt from not purchasing the greenest product) are fed back into the consumer's general green values and knowledge, which influences the next purchase (Young \& Hwang, 2008). Knowledge might act as a mediating variable for ecological attitudes and behavior. In addition, augmented knowledge of environmental issues may lead to more positive ecological attitudes (Chan, 2001).

\section{$H_{3}$ : Environmental knowledge has a positive effect on consumer's attitudes towards green products.}

\subsubsection{Environmental Concern}

Fundamental to environmental research is an individual's concern for the environment. Based on the pioneering research of Dunlap and Van Liere, environmental concern is defined as a global attitude with indirect effects on behavior through behavioral intention. Some other researchers mentioned that environmental concern is a strong attitude towards preserving the environment (Kaufmann et al., 2012).

Grunert and Juhl define an environmentally concerned consumer as one "who knows that the production, distribution, use, and disposal of products lead to external costs, and who evaluates such external costs negatively, trying to minimize them by her/his own behavior". Environmental concern is often cited as a strong motivator for purchase. Huang recommends that the increased consumption of organic produce is related to an increased concern for environmental issues within society. This is supported by Tregear et al. who found that purchasers of green products were more likely to engage in environmentally friendly activities like recycling in order to demonstrate their environmental 
concern (Smith \& Paladino, 2010). In general, evidence from different sectors shows that people's purchasing behavior is influenced by environmental concerns (Mayer et al., 2012).

$H_{4}$ : Environmental concern has a positive effect on consumer's attitudes towards green products.

\subsubsection{Perceived Innovation Characteristic:}

Environmental innovation or green innovation refers to those environmental practices incorporated into a company's policies to guide products, production process and management. From the perspective of innovation, adopting environmental technologies is the primary way to protect the environment from the harmful impact of corporations (Choua et al., 2012). With regard to innovation, the following perceived innovation characteristics (PIC) are distinguished;

\begin{tabular}{|c|c|c|}
\hline Characteristic & Definition & Reference \\
\hline $\begin{array}{l}\text { Relative } \\
\text { advantage }\end{array}$ & $\begin{array}{l}\text { Degree to which an innovation is seen as being superior to its } \\
\text { predecessor. }\end{array}$ & $\begin{array}{l}\text { Hebert \& } \\
\text { Benbasat } 1994\end{array}$ \\
\hline Compatibility & $\begin{array}{l}\text { Degree to which an innovation is seen to be compatible with } \\
\text { existing values, beliefs, experiences and needs of adopters. }\end{array}$ & $\begin{array}{l}\text { Todd \& } \\
\text { Taylor,1995 }\end{array}$ \\
\hline Complexity & $\begin{array}{l}\text { Degree to which an innovation is seen by the potential adopter } \\
\text { as being relatively difficult to use and understand. }\end{array}$ & Grover, 1993 \\
\hline Visibility & $\begin{array}{l}\text { The perception of the actual visibility of the innovation itself as } \\
\text { opposed to the visibility of outputs. }\end{array}$ & $\begin{array}{l}\text { Agarwal \& } \\
\text { Prasad, } 1997\end{array}$ \\
\hline Trial-ability & $\begin{array}{l}\text { Based on adopters' perceptions of the degree to which an } \\
\text { innovation can be used on a trial basis before confirmation of } \\
\text { the adoption must occur. }\end{array}$ & Teo et al., 1995 \\
\hline $\begin{array}{l}\text { Result } \\
\text { demonstrability }\end{array}$ & $\begin{array}{l}\text { Degree to which the results of using an innovation are } \\
\text { perceived to be tangible. }\end{array}$ & $\begin{array}{l}\text { Hebert \& } \\
\text { Benbasat, } 1994\end{array}$ \\
\hline Image & $\begin{array}{l}\text { Degree to which the use of the innovation is seen as enhancing } \\
\text { to an individual's image or social status. }\end{array}$ & $\begin{array}{l}\text { Van Slyke er } \\
\text { al., } 2002\end{array}$ \\
\hline Voluntariness & $\begin{array}{l}\text { Degree to which use of an innovation is perceived as being of } \\
\text { free will. }\end{array}$ & $\begin{array}{l}\text { Agarwal \& } \\
\text { Prasad,1997 }\end{array}$ \\
\hline
\end{tabular}

Based on the TRA model, the intention to adopt green practices is associated with the consumer's attitudes towards the environmental innovation. Previous studies assume that perceived innovation characteristics directly influence innovation adoption. However, Rogers notes that, in the decisionmaking process of innovation adoption, the formation of a specific attitude toward the innovation is a key element in affecting its adoption. Furthermore, the perceived innovation characteristics can be considered the cognitive indicators of attitude toward an innovation (Choua et al., 2012).

$H_{5}$ : Perceived innovation characteristics have a positive effect on consumer's attitudes towards green products.

\subsubsection{Quality}

Product attributes such as convenience, availability and quality play an important role in the consumers' purchasing decision process (Gan et al., 2008). A consumer's choice for or against organic products can be framed as a social dilemma, in which he or she must weigh individual motives, such as quality considerations. The perceived level of quality, which is an overall evaluative judgment of a product's items and a key dimension in product choice (Doorn \& Verhoef, 2011). The product quality can be a good starting point for providing customer satisfaction and producing customer loyalty. Johnson and Ettlie explained that product quality as the result of performance, 
which, in turn can be labeled as the degree of customization and freedom from defects or how reliably the product met customer requirements. The product quality dimension included product packaging, product design, product features, warranties, etc. Many companies can not only embody green or environmental concept in the feature, design, and package of their product to increase product differentiation, but they should also satisfy the environmental requirements of customers and further create customer loyalty as well as a competitive advantage (Chang \& Fong, 2010).

H6: Quality has a positive effect on consumer's attitudes towards green products.

\subsubsection{Green advertising}

A number of organizations demonstrate their environmental sensitivity with various strategies. One of the marketing tools implemented by organizations is environmental or green advertising. Neff and Thompson state that eco-marketing will have staying power this time around. They feel that consumers who were not willing to pay more for green products in the past are willing to do so now. Their findings demonstrated that support for green products from top retailers, such as Wal-Mart, Home Depot, and Kroger Co. is making a difference in consumer attitudes (Haytko \& Matulich , 2008). Promoting green products is a tender balance of giving the consumer too much information and overwhelming them and not giving consumers enough information, making them skeptical of environmental claims. Further, other product attributes must be coordinated with the environmental attributes in order for promotion to be successful.

'Green advertising' must meet one or more of the following criteria:

- Explicitly or implicitly addresses the relationship between a product or service and the biophysical environment;

- Promotes a green lifestyle with or without highlighting a product or service; and

- Presents a corporate image of environmental responsibility (Gomon, 2005).

Audience behavior towards the advertising can be indicated through consumers' favorable or unfavorable response towards a particular advertisement. According to Mehta, consumers' attitude towards advertising is one of the influential indicators of advertising effectiveness because consumer's cognitive ability towards the advertising are reflected in their thoughts and feelings and subsequently will influence their attitude towards advertising (Ling et al., 2010).

\section{$H_{7}$ : Green advertising has a positive effect on consumer's attitudes towards green products.}

\subsubsection{Green labeling:}

The environmental attributes of a product are more difficult for a consumer to assess compared with other easily observable product attributes. A report by the Massachusetts Department of Environmental Protection recommends that the difficulty in detecting and locating green products is one of the barriers to green product purchases. One way to overcome this issue is to utilize ecolabeling (or green labeling) programs to provide the customers with information while at the same time addressing environmental issues. An eco-label is a voluntary claim that a product has less impact on the environment with either production or consumption of that product (Gan et al., 2008). Energy conservation, agricultural products, degradable, non-toxic plastic packaging material, hazardous metal-free electrical and electronic equipment, biodegradable cleaning agents and recycled paper ware are some schemes associated with eco-labeling that classified by SIRIM (Standards and Industrial Research Institute of Malaysia) (Mei et al., 2012).

Rashid in his study, which introduced eco label as a separate variable found that eco label is an important factor that would enable consumers to make right purchase choice if faced with a situation 
that require their consideration of the environmental impact on product they wish to purchase (Abdul Vahid et al. 2011). In addition, previous studies show that consumers would purchase and are willing to pay more for green labeled products. However, green labeled products also contain potential dangers and drawbacks, especially when producers over-claim ecological responsibility or performance (Gan et al., 2008).

$H_{8}$ : Green labeling has a positive effect on consumer's attitudes towards green products.

\section{Conceptual model}

With reference to the foregoing literature review, a conceptual model is proposed in Fig. 1 to explain Iranian consumers' green purchase behavior.

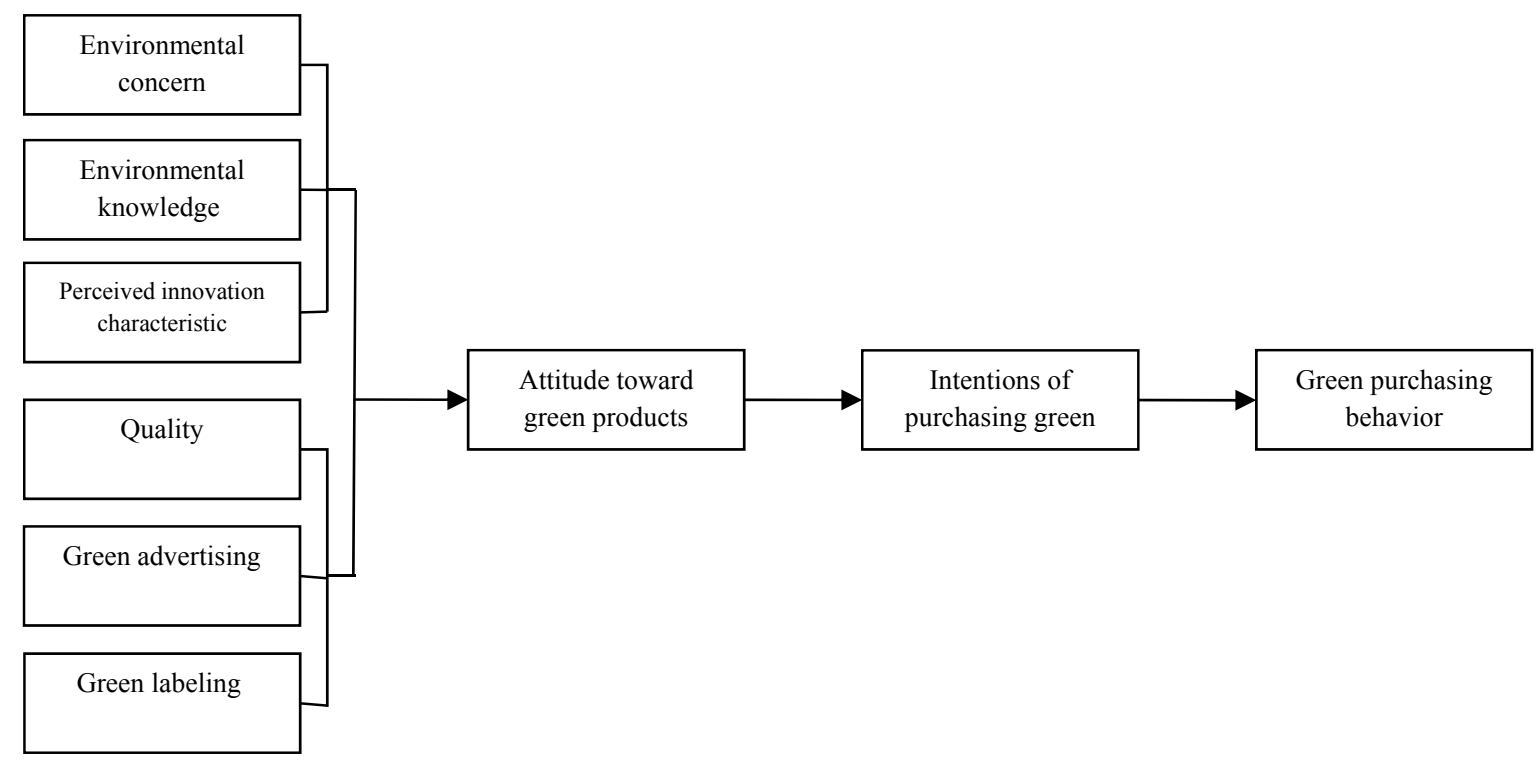

Fig. 1. Conceptual model of green purchasing behavior

\section{Methodology}

Data were collected from a convenience sample of 374 consumers from the Guilan province in Iran using a self-completion questionnaire. The confidence coefficient value was calculated using Cronbach's alpha method and in order to assess the validity of the questions, factor validity was used. Factor validity is a form of structural validity which is obtained through factor analysis. We analyzed our conceptual model using structural equation modeling (SEM). SEM is a technique embracing both dependence and interdependence relationships, which can be considered as an extension to multiple regression. The technique estimates a series of regression equations simultaneously, where these equations are separate but interdependent. A unique property of the technique is its ability to accommodate a series of interrelated dependence relationships (i.e. layering). The technique also incorporates factor analysis, with the aim of explaining constructs or latent factors, which are not directly observable, but are modeled through a set of indicator or reflective variables (Michaelidou \& Hassan, 2010).

\section{Result and discussion}

As noted, all constructs were assessed using 5-point Likert type scales. Table 1 shows the descriptive statistics, composite reliability and average variance extracted (AVE) for the model constructs. The convergent and discriminant validity of all variables were be tested by confirmatory factor analysis using the maximum likelihood estimator of LISREL 8.73. The discriminant validity of the scales was 
checked by the Fornell and Larker's formula. Discriminant validity is present when the AVE from each construct is greater than the square of the intercorrelations. The measurement properties of the all scales indicate that the factor loadings are high and statistically significant. These results satisfy the criteria for convergent validity.

\section{Table 1}

Means, standard deviations, Cronbach's alpha, Average Variance Extracted an Composite Reliability

\begin{tabular}{llllll}
\hline Construct & AVE & Composite Reliability & Cronbach Alpha & Mean & Sd \\
\hline Attitude & 0.699 & 0.921 & 0.891 & 2.916 & 1.108 \\
\hline Environmental concern & 0.651 & 0.903 & 0.865 & 2.714 & 0.951 \\
Green labeling & 0.626 & 0.909 & 0.880 & 2.584 & 0.900 \\
Green purchasing behavior & 0.792 & 0.920 & 0.869 & 2.800 & 1.079 \\
Intentions of purchasing green & 0.714 & 0.909 & 0.865 & 2.835 & 1.041 \\
Knowledge & 0.573 & 0.842 & 0.750 & 2.637 & 0.802 \\
Perceived innovation characteristics & 0.612 & 0.904 & 0.873 & 2.652 & 0.881 \\
Quality & 0.707 & 0.906 & 0.862 & 2.648 & 0.963 \\
\hline
\end{tabular}

Structural model analysis LISREL was used to create the covariance-based structural equation model (SEM). LISREL also provides a number of model fit indices. The incremental fit index (IFI), which tests the improvement of the model over a baseline model (usually a model of independence or uncorrelated variables), relative fit index (RFI) which compares a chi-square for the model tested to one from a baseline model, variations of RFI (which are not explicitly designed to be provide penalties for less parsimonious models) such as the normed fit index (NFI) and non-normed fit index (NNFI or TLI), and no centrality-based indices whereby the no centrality parameter is calculated by subtracting the degrees of freedom in the model from the chi-square $(\chi 2 / \mathrm{df})$ such as the comparative fit index (CFI), and root-meansquare error of approximation index (RMSEA). Values greater than 0.90 are desirable for IFI, RFI, CFI, NFI and NNFI while values less than 0.09 for RMSEA are acceptable. The result of models indices support a good overall model fit and shows that at the Table 4 and Fig1. Goodness of fit statistics shows the indices obtained for the model, and indicates that the model applied was quite acceptable. LISREL VIII was used to estimate the main effects of the model (see Fig. 2). In a confirmatory factor analysis (CFA) by LISREL, Discriminant validity is shown when: (1) measurement items load more strongly on their assigned construct than on the other constructs in a CFA(result of Table 3); and, (2) the square root of the average variance extracted (AVE) of each construct is larger than its correlations with the other constructs. Conformational factor analysis tool is used in order to analyze the internal structure of the questionnaire and discover the constituents of each latent structure or variable. The conformational factor analysis of the research's structures is presented in Fig. 2.

According to the results of this Fig, all of factor loadings related to "latent variables" structure are meaningful on $99 \%$ reliability coefficient and all are more than .60 . In order to assess the reliability of measurement items, we compute composite construct reliability coefficients and Cronbachs Alpha. Composite reliabilities range from 0.842 (for Knowledge) to 0.921 (for Attitude), which exceed the recommended level of 0.70 . The results (see Table 1), therefore, demonstrate a reasonable reliability level of the measured items. The study model with the path coefficients and significance levels are given in Fig. 2. In order to test the hypotheses, we examined the coefficients of the causal relationships between constructs, which would validate the hypothesized effects. Fig. 2 and Table 3 illustrate the paths and their significance on the structural model. As shown in Fig. 2 and Table 4, $\mathrm{H}_{1}$ and $\mathrm{H}_{2}$ were supported at the $1 \%$ significance level, these suggest that intentions of green purchasing do influence green purchasing behavior and attitudes do influence purchase intentions. These findings are also consistent with other research conducted (Smith \& Paladino, 2010). The results obtained for the some antecedents will now be investigated. The first variable examined was environmental knowledge, which is concerned with $\mathrm{H}_{3} . \mathrm{H}_{3}$, which specifies the relationship between environmental knowledge and attitudes was not supported at the 5\% level. This finding is inconsistent with past research that shows environmental knowledge has a positive impact on green purchase decisions 
(Chan, 2001). $\mathrm{H}_{4}$ examined the influence environmental concern has on attitudes that was supported at the $5 \%$ level. This is consistent with past research that has found the consumers purchase green products for environmental concern ( Smith \& Paladino, 2010).

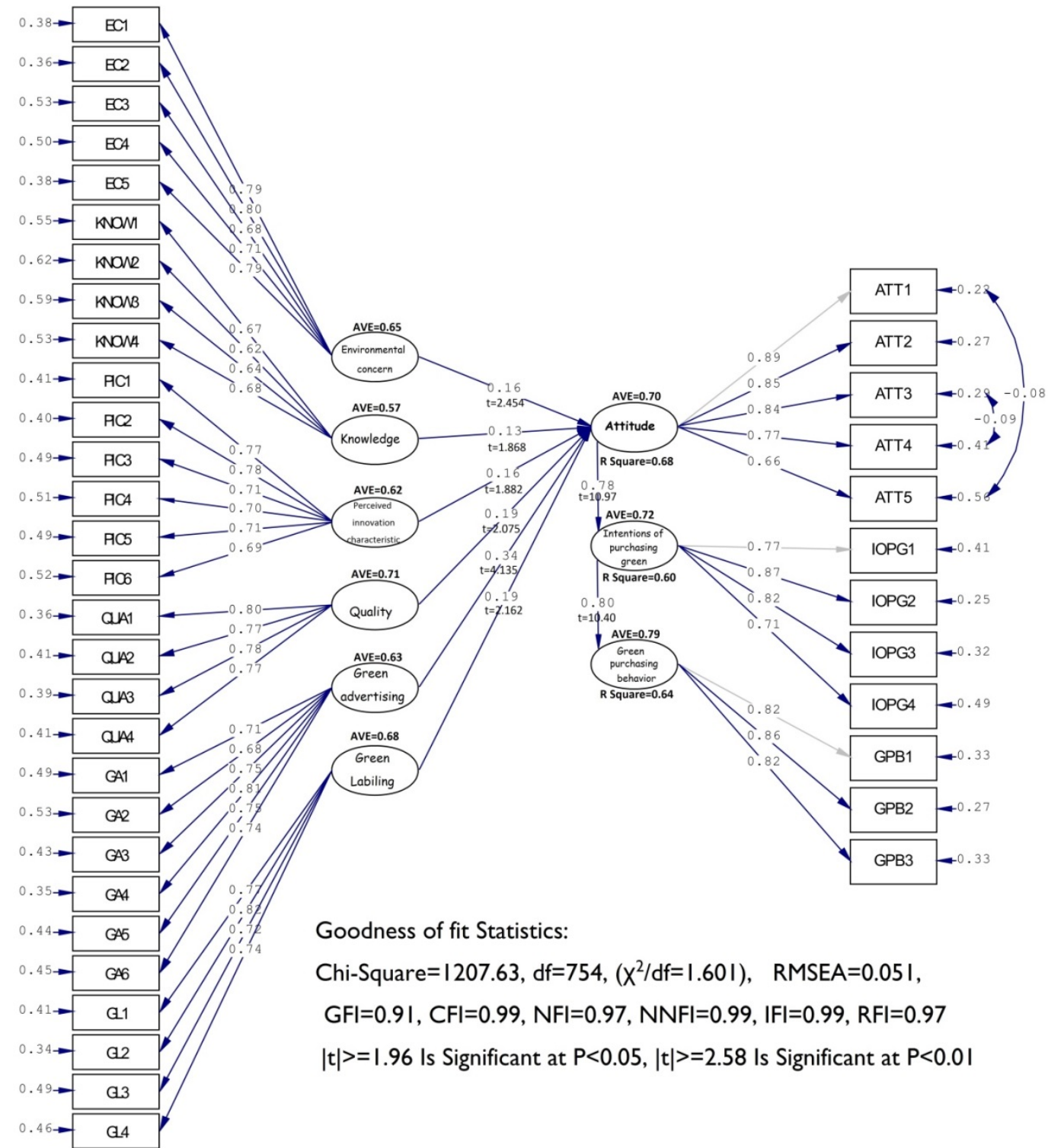

Fig. 2. Research Model in Estimation and Significant situation

Perceived Innovation Characteristic was investigated in the form of $\mathrm{H}_{5} . \mathrm{H}_{5}$ was not supported at 5\% level suggesting that perceived innovation characteristics have a positive effect on consumer's attitudes towards green products. This finding is not consistent with Chou et al.'s study (2012) that was proved this relationship. The impact of quality on attitude $\left(\mathrm{H}_{6}\right)$ was supported at $5 \%$ level and consistent with past research (Chang \& Fong, 2010). $\mathrm{H}_{7}$ was supported at the $1 \%$ significant level. This hypothesis suggests that green advertising has a positive effect on consumer's attitudes. Finally, green labeling was investigated in $\mathrm{H}_{8} . \mathrm{H}_{8}$ was found to be significant at the $5 \%$ significance level. This finding shows that green labeling has a positive effect on consumer's attitudes towards green products. In statistics, a value is often required to determine how closely a certain function fits a particular set of experimental data. In this module, we have relied on the $\mathrm{R}^{2}$ value, computed in LISREL to determine how closely our data conform to a linear relationship. $\mathrm{R}^{2}$ values range from 0 to 1 , with 1 representing a perfect fit between the data and the line drawn through them, and 0 representing no statistical correlation between the data and a line. Approximately, $68 \%$ of the variance Attitude $\left(\mathrm{R}^{2}=0.68\right)$ is explained by Environmental concern, Green advertising, Green 
labeling, Knowledge, Perceived innovation characteristic and Quality. Approximately, 72\% of the variance Intentions of purchasing green $\left(\mathrm{R}^{2}=0.60\right)$ is explained by Attitude and Approximately, $64 \%$ of the variance Green purchasing behavior $\left(\mathrm{R}^{2}=0.64\right)$ is explained by Intentions of purchasing green.

Table 2

Latent Variable Correlations

\begin{tabular}{|c|c|c|c|c|c|c|c|c|c|}
\hline Construct & $\begin{array}{l}\text { D. } \\
\text { 言 }\end{array}$ & 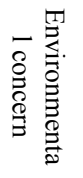 & 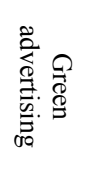 & 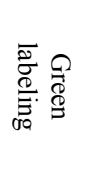 & 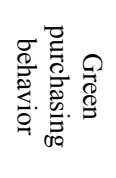 & 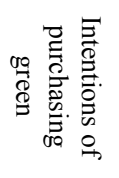 & 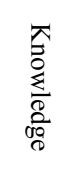 & 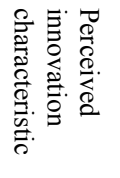 & 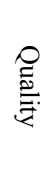 \\
\hline Attitude & 1 & & & & & & & & \\
\hline Environmental concern & 0.666 & 1 & & & & & & & \\
\hline Green advertising & 0.737 & 0.581 & 1 & & & & & & \\
\hline Green labeling & 0.74 & 0.677 & 0.739 & 1 & & & & & \\
\hline Green purchasing behavior & 0.566 & 0.481 & 0.375 & 0.462 & 1 & & & & \\
\hline Intentions of purchasing green & 0.739 & 0.528 & 0.506 & 0.52 & 0.71 & 1 & & & \\
\hline Knowledge & 0.627 & 0.789 & 0.674 & 0.669 & 0.421 & 0.479 & 1 & & \\
\hline Perceived innovation characteristic & 0.727 & 0.821 & 0.672 & 0.769 & 0.479 & 0.546 & 0.788 & 1 & \\
\hline Quality & 0.748 & 0.749 & 0.729 & 0.779 & 0.455 & 0.519 & 0.738 & 0.819 & 1 \\
\hline
\end{tabular}

Table 3

Cross Loading

\begin{tabular}{|c|c|c|c|c|c|c|c|c|c|}
\hline Construct & Attitude & $\begin{array}{l}\text { Environmental } \\
\text { concern }\end{array}$ & $\begin{array}{c}\text { Green } \\
\text { advertising }\end{array}$ & $\begin{array}{c}\text { Green } \\
\text { labeling }\end{array}$ & $\begin{array}{c}\text { Green purchasing } \\
\text { behavior }\end{array}$ & $\begin{array}{c}\text { Intentions of } \\
\text { purchasing green }\end{array}$ & Knowledge & $\begin{array}{l}\text { Perceived innovation } \\
\text { characteristic }\end{array}$ & Quality \\
\hline Att1 & 0.886 & 0.638 & 0.697 & 0.665 & 0.481 & 0.613 & 0.596 & 0.691 & 0.725 \\
\hline Att3 & 0.861 & 0.570 & 0.655 & 0.680 & 0.441 & 0.563 & 0.538 & 0.621 & 0.663 \\
\hline Att4 & 0.806 & 0.553 & 0.611 & 0.611 & 0.473 & 0.675 & 0.532 & 0.622 & 0.615 \\
\hline Att5 & 0.738 & 0.412 & 0.422 & 0.449 & 0.532 & 0.690 & 0.370 & 0.430 & 0.383 \\
\hline Ec1 & 0.518 & 0.840 & 0.417 & 0.501 & 0.380 & 0.412 & 0.624 & 0.687 & 0.583 \\
\hline Ec2 & 0.580 & 0.852 & 0.470 & 0.564 & 0.378 & 0.438 & 0.657 & 0.659 & 0.635 \\
\hline Ec3 & 0.449 & 0.765 & 0.431 & 0.527 & 0.299 & 0.348 & 0.557 & 0.565 & 0.539 \\
\hline Ec4 & 0.522 & 0.739 & 0.509 & 0.559 & 0.370 & 0.410 & 0.660 & 0.686 & 0.615 \\
\hline Ec5 & 0.595 & 0.831 & 0.511 & 0.575 & 0.491 & 0.502 & 0.670 & 0.701 & 0.639 \\
\hline GA1 & 0.526 & 0.435 & 0.758 & 0.617 & 0.297 & 0.321 & 0.505 & 0.550 & 0.619 \\
\hline GA2 & 0.501 & 0.464 & 0.740 & 0.499 & 0.241 & 0.370 & 0.551 & 0.490 & 0.556 \\
\hline GA3 & 0.584 & 0.515 & 0.803 & 0.570 & 0.317 & 0.403 & 0.590 & 0.588 & 0.608 \\
\hline GA4 & 0.651 & 0.479 & 0.842 & 0.626 & 0.297 & 0.447 & 0.548 & 0.541 & 0.613 \\
\hline GA6 & 0.628 & 0.469 & 0.792 & 0.601 & 0.310 & 0.415 & 0.535 & 0.541 & 0.556 \\
\hline GL1 & 0.609 & 0.650 & 0.614 & 0.799 & 0.344 & 0.385 & 0.651 & 0.683 & 0.694 \\
\hline GL2 & 0.614 & 0.550 & 0.653 & 0.883 & 0.386 & 0.410 & 0.528 & 0.642 & 0.646 \\
\hline GL3 & 0.568 & 0.496 & 0.571 & 0.801 & 0.353 & 0.437 & 0.507 & 0.592 & 0.586 \\
\hline GL4 & 0.641 & 0.530 & 0.593 & 0.809 & 0.434 & 0.477 & 0.515 & 0.612 & 0.637 \\
\hline GPB1 & 0.498 & 0.405 & 0.303 & 0.399 & 0.885 & 0.622 & 0.357 & 0.435 & 0.394 \\
\hline GPB2 & 0.529 & 0.477 & 0.378 & 0.438 & 0.900 & 0.645 & 0.421 & 0.453 & 0.463 \\
\hline GPB3 & 0.484 & 0.401 & 0.319 & 0.397 & 0.885 & 0.630 & 0.343 & 0.391 & 0.356 \\
\hline IOPG1 & 0.682 & 0.445 & 0.464 & 0.463 & 0.527 & 0.821 & 0.414 & 0.410 & 0.409 \\
\hline IOPG2 & 0.646 & 0.446 & 0.424 & 0.448 & 0.640 & 0.900 & 0.418 & 0.487 & 0.476 \\
\hline IOPG3 & 0.639 & 0.484 & 0.467 & 0.459 & 0.601 & 0.871 & 0.421 & 0.481 & 0.478 \\
\hline IOPG4 & 0.526 & 0.407 & 0.351 & 0.383 & 0.634 & 0.782 & 0.363 & 0.467 & 0.388 \\
\hline Know1 & 0.457 & 0.651 & 0.447 & 0.514 & 0.325 & 0.340 & 0.723 & 0.620 & 0.588 \\
\hline Know2 & 0.473 & 0.531 & 0.594 & 0.489 & 0.233 & 0.351 & 0.728 & 0.545 & 0.513 \\
\hline Know3 & 0.442 & 0.618 & 0.471 & 0.449 & 0.372 & 0.391 & 0.756 & 0.565 & 0.519 \\
\hline Know4 & 0.520 & 0.592 & 0.523 & 0.564 & 0.345 & 0.370 & 0.817 & 0.652 & 0.609 \\
\hline Pic2 & 0.614 & 0.663 & 0.530 & 0.625 & 0.408 & 0.464 & 0.650 & 0.830 & 0.694 \\
\hline Pic3 & 0.584 & 0.673 & 0.512 & 0.582 & 0.419 & 0.471 & 0.595 & 0.782 & 0.580 \\
\hline Pic4 & 0.543 & 0.567 & 0.522 & 0.606 & 0.306 & 0.345 & 0.564 & 0.787 & 0.604 \\
\hline Pic5 & 0.566 & 0.651 & 0.544 & 0.598 & 0.365 & 0.421 & 0.599 & 0.766 & 0.646 \\
\hline Pic6 & 0.503 & 0.586 & 0.556 & 0.570 & 0.333 & 0.362 & 0.641 & 0.744 & 0.618 \\
\hline Qua1 & 0.623 & 0.703 & 0.609 & 0.656 & 0.485 & 0.473 & 0.714 & 0.758 & 0.821 \\
\hline Qua2 & 0.628 & 0.610 & 0.598 & 0.658 & 0.372 & 0.421 & 0.621 & 0.661 & 0.839 \\
\hline Qua3 & 0.660 & 0.597 & 0.616 & 0.667 & 0.352 & 0.438 & 0.569 & 0.669 & 0.858 \\
\hline Qua4 & 0.600 & 0.611 & 0.628 & 0.638 & 0.320 & 0.414 & 0.580 & 0.665 & 0.844 \\
\hline
\end{tabular}


Table 4

Path coefficients, t-value, Goodness of fit Statistics and result

\begin{tabular}{lccc}
\hline Hypothesis & Path coefficients & T-value & Result \\
\hline Environmental concern $\rightarrow$ Attitude(H1) & 0.16 & $2.454^{*}$ & Supported \\
Green advertising $\rightarrow$ Attitude(H2) & 0.34 & $4.135^{* *}$ & Supported \\
Green labeling $\rightarrow$ Attitude $(\mathrm{H} 3)$ & 0.19 & $2.162^{*}$ & Supported \\
Knowledge $\rightarrow$ Attitude $(\mathrm{H} 4)$ & 0.13 & 1.868 & Not Supported \\
Perceived innovation characteristic $\rightarrow$ Attitude(H5) & 0.16 & 1.882 & Not Supported \\
Quality $\rightarrow$ Attitude $(H 6)$ & 0.19 & $2.075^{*}$ & Supported \\
Attitude $\rightarrow$ Intentions of purchasing green $(H 7)$ & 0.78 & $10.97^{* *}$ & Supported \\
intentions of purchasing green $\rightarrow$ Intentions of purchasing green $(\mathrm{H} 8)$ & 0.80 & $10.40^{* *}$ & Supported \\
\hline
\end{tabular}

Goodness of fit Statistics:

Chi-Square $=1207.63, \mathrm{df}=754,\left(\chi^{2} / \mathrm{df}=1.601\right), \mathrm{RMSEA}=0.051, \mathrm{GFI}=0.91, \mathrm{CFI}=0.99, \mathrm{NFI}=0.97, \mathrm{NNFI}=0.99$, IFI $=0.99$, RFI $=0.97$

$*|t|>=1.96$ is Significant at $\mathrm{p} 0.05$ level, $* *|t|>=2.58$ is significant at $\mathrm{p} 0.01$ level.

\section{Conclusion}

The theory of Reasoned Action (TRA) proved its applicability in explaining social behavior aimed at green products purchases. The TRA model was tested on a large representative sample of consumers from Guilan province and its predictive ability corresponds with other examples. The best predictors of the intention to purchase green products are attitudes towards the behavior. This study shows that the intention of consumers to purchase green products is determined by having a positive attitude toward green products. The present study also has examined the influence of various personal and marketing factors on the attitude toward green products of consumers from Guilan province. The results from the structural-equation modeling show the environmental concern is the only personal factor that influence on attitude towards green products among three personal variables including environmental knowledge, environmental concern and perceived innovation characteristics. It confirms the significant influence of all tree marketing variables including quality, green advertising and green labeling on attitudes toward green products. The results of this research have implications for the marketing of these products to consumers and for researchers. Marketers of green products should link these products with concern for environmental issues within society to promote these products.

\section{References}

Abdul Vahid, N., Rahbar E., and Shyan T. (2011). Factors influencing the green purchase behavior of Penang environmental volunteers. International Business Management, 5(1), 38-49

Agarwal, R., \& Prasad J. (1997). Role of innovation characteristics and perceived voluntariness in the acceptance of information technologies. Decision Sciences, 28(3), 557-582.

Chan, R. Y. K. (2001). Determinants of Chinese consumers' green purchase behavior. Psychology \& Marketing, 18(4), 389-413.

Chang, N., \& Fong, Ch. (2010). Green product quality, green corporate image, green customer satisfaction, and green customer loyalty. African Journal of Business Management, 4(13), 2836-2844.

Chen, T., \& Teck Chai L. (2010). Attitude towards the environment and green products: Consumers' perspective. Management Science and Engineering, 4(2), 27-39.

Chou, Ch., Chena K., \& Wang Y. (2012). Green practices in the restaurant industry from an innovation adoption perspective: Evidence from Taiwan. International Journal of Hospitality Management, 31, 703-711.

Doorn, J., \& Verhoef P. C. (2011). Willingness to pay for organic products: Differences between virtue and vice foods. International Journal of Research in Marketing, 28, 167-180.

Drozdenko, R., Jensen M., and Coelho D. (2011). Pricing of green products: Premiums paid, Consumer characteristics and incentives. International Journal of Business, Marketing, and Decision Sciences, 4(1), 106-116. 
Gan, C., Wee, H. Y., Ozanne, L., \& Kao, T. H. (2008). Consumers' purchasing behavior towards green products in New Zealand. Innovative Marketing, 4(1), 93-102.

Gomon, S. (2005). The Influence of promotional brochures and pricing strategies on consumer purchase decisions for forest stewardship council certified hardwood boards in home centers. M. S. thesis, Virginia Polytechnic Institute and State University, VA.

Grover, V. (1993). An empirically derived model for the adoption of customer-based interorganizational systems. Decision Sciences, 24(3), 603-640.

Han, H., Hsu L., \& Sheu, Ch. (2010). Application of the theory of planned behavior to green hotel choice: Testing the effect of environmental friendly activities. Tourism Management, 31, 325-334.

Han, H., \& Kim Y. (2010). An investigation of green hotel customers' decision formation: Developing an extended model of the theory of planned behavior. International Journal of Hospitality Management, 29, 659-668.

Han, H., Hsu L., Lee J., \& Sheu Ch. (2011). Are lodging customers ready to go green? An examination of attitudes, demographics, and eco-friendly intentions. International Journal of Hospitality Management, $30,345-355$.

Haytko, D. L., \& Matulich, E. (2008). Green advertising and environmentally responsible consumer behaviors: Linkages examined. Journal of Management and Marketing Research, 1(1), 5-14.

Hebert, M., \& Benbasat, I. (1994). Adopting information technology in hospitals: The relationship between attitudes/expectations and behavior. Hospital \& Health Services Administration, 39(3), 369383.

Kaufmann, H., Ruediger A., Fateh M., \& Yianna O. (2012). Factors affecting consumers' green purchasing behavior: An integrated conceptual framework. Amfiteatru Economic, 14(31), 50-69.

Ling, K. C., Piew, T. H., \& Chai, L. T. (2010). The determinants of consumers' attitude towards advertising. Canadian Social Science, 6(4), 114-126.

Mayer, R., Ryley T., \& Gillingwater, D. (2012). Passenger perceptions of the green image associated with airlines. Journal of Transport Geography, 22. 179-186.

Mei, O. J., Ling, K. C., \& Piew, T. H. (2012). The Antecedents of Green Purchase Intention among Malaysian Consumers. Asian Social Science, 8(13), 246.

Michaelidou, N., \& Hassan L. M.(2010). Modeling the factors affecting rural consumers' purchase of organic and free-range produce: A case study of consumers' from the Island of Arran in Scotland, UK. Food Policy, 35, 130-139.

OSEC (2009), The US market for green technologies; Opportunities and challenges for Swiss companies. Kansas City: Biofuels Business

Ramayah, T., Lee, J. W. C., \& Mohamad, O. (2010). Green product purchase intention: Some insights from a developing country. Resources, Conservation and Recycling, 54(12), 1419-1427.

Shah, N (2002). Green purchasing http://www.hshieldsconsulting.com/

Smith, S., \& Paladino, A. (2010). Eating clean and green? Investigating consumer motivations towards the purchase of organic food. Australasian Marketing Journal (AMJ), 18(2), 93-104.

Sua, J. C. P., Wang, L., \& Ho J. C. (2012). The impacts of technology evolution on market structure for green products. Mathematical and Computer Modelling, 55, 1381-1400.

Taylor, S., \& Todd P.A. (1995). Understanding information technology usage: A test of competing models. Information Systems Research, 6(2), 144-176.

Teo, H., Tan, B., \& Wei, K. (1995). Innovation diffusion theory as a predictor of adoption intention for financial EDI. Proceedings of the 16th Annual International Conference on Information Systems, Amsterdam, Netherlands, 155-165.

Van Slyke, C., Comunale, C. L., \& Belanger, F. (2002). Gender differences in perceptions of web-based shopping. Communications of the ACM, 45(8), 82-86.

Young, W., Hwang, K., McDonald, S., \& Oates, C. J. (2010). Sustainable consumption: green consumer behaviour when purchasing products. Sustainable Development, 18(1), 20-31.

Zakersalehi, M., \& Zakersalehi, A. (2012). Consumers' attitude and purchasing intention toward green packaged foods; A Malaysian perspective. International Conference on Economics Marketing and Management, 28. 